\title{
On the Hilbert quasi-polynomials of non-standard graded rings
}

Let $R:=\mathbb{K}\left[x_{1}, \ldots, x_{k}\right], I$ be an homogeneous ideal of $R$. The numerical function $H_{R / I}: \mathbb{N} \rightarrow \mathbb{N}$ defined by $H_{R / I}(d):=\operatorname{dim}_{\mathbb{K}}\left((R / I)_{d}\right)$ is called Hilbert function of $R / I$. It is eventually a polynomial, $H P_{R}$.

$$
R=\mathbb{Q}\left[x_{1}, \ldots, x_{5}\right], \text { graded by }[1,1,1,1,1] \text { (standard grading) }
$$

$$
H P_{R}=1 / 24 x^{4}+5 / 12 x^{3}+35 / 24 x^{2}+25 / 12 x+1
$$

$R$ graded by $W=[1,2,3,4,6] . H P_{R}^{W}(n)=P_{n} \bmod 12(n)$

$$
\begin{aligned}
H P_{R}^{W}=\left[P_{0}(x)\right. & =1 / 3456 x^{4}+1 / 108 x^{3}+5 / 48 x^{2}+1 / 2 x+1, \\
& P_{1}(x)=1 / 3456 x^{4}+1 / 108 x^{3}+19 / 192 x^{2}+43 / 108 x+1705 / 3456, \\
& P_{2}(x)=1 / 3456 x^{4}+1 / 108 x^{3}+5 / 48 x^{2}+25 / 54 x+125 / 216, \\
& P_{3}(x)=1 / 3456 x^{4}+1 / 108 x^{3}+19 / 192 x^{2}+5 / 12 x+75 / 128, \\
& P_{4}(x)=1 / 3456 x^{4}+1 / 108 x^{3}+5 / 48 x^{2}+13 / 27 x+20 / 27 . \\
& P_{5}(x)=1 / 3456 x^{4}+1 / 108 x^{3}+19 / 192 x^{2}+41 / 108 x+1001 / 3456, \\
& P_{6}(x)=1 / 3456 x^{4}+1 / 108 x^{3}+5 / 48 x^{2}+1 / 2 x+7 / 8, \\
& P_{7}(x)=1 / 3456 x^{4}+1 / 108 x^{3}+19 / 192 x^{2}+43 / 108 x+1705 / 3456, \\
& P_{8}(x)=1 / 3456 x^{4}+1 / 108 x^{3}+5 / 48 x^{2}+25 / 54 x+19 / 27, \\
& P_{9}(x)=1 / 3456 x^{4}+1 / 108 x^{3}+19 / 192 x^{2}+5 / 12 x+75 / 128, \\
& P_{10}(x)=1 / 3456 x^{4}+1 / 108 x^{3}+5 / 48 x^{2}+13 / 27 x+133 / 216, \\
& \left.P_{11}(x)=1 / 3456 x^{4}+1 / 108 x^{3}+19 / 192 x^{2}+41 / 108 x+1001 / 3456\right]
\end{aligned}
$$

- $d=\operatorname{lcm}(1,2,3,4,6)=12, \delta_{3}=\delta_{4}=1, \delta_{0}=12$

- $\delta_{2}=2=\operatorname{lcm}(2) \quad(\{2,4,6\})$

- $\delta_{1}=6=\operatorname{lcm}(2,2,3,2)$ 